\title{
Screening and brief intervention delivered simultaneously in multiple settings: it is cost-effective, but can it influence community-level outcomes?
}

\author{
Anthony Shakeshaft
}

From International Network on Brief Interventions for Alcohol Problems (INEBRIA) Meeting 2011

Boston, MA, USA. 21-23 September 2011

A 20-community randomized controlled trial, the Alcohol Action in Rural Communities (AARC) project, provided the opportunity to examine the cost-effectiveness of screening and brief intervention (SBI) delivered simultaneously in general practice (GP), pharmacy, and emergency department (ED) settings and the community level impact of the SBI on problem drinking. For the GP- and pharmacy-delivered SBI, decision models and scenario analysis assessed outcomes and costs in the 10 experimental communities of the trial. For the ED-delivered SBI, a randomized controlled trial design was used to examine the cost-effectiveness of mailed personalized feedback. For both the GP- and pharmacy-delivered SBI, the most costeffective outcome was to increase screening alone: GPs and pharmacies screening all patients achieved an incremental cost-effectiveness ratio (ICER) of AUD \$197 and AUD \$29, respectively, per risky drinker who reduced drinking. The ED-based SBI resulted in a reduction of 2.6 fewer drinks per week at an average cost of $\$ 5.55$ per patient and an ICER of $\$ 2.13$ per one standard drink reduction in average weekly consumption. In addition to cost-effectiveness, the AARC community approach provided the opportunity to analyze the effect of SBI on community level outcomes. Currently, $19 \%$ of risky drinkers in a community visit a GP and reduce their drinking, which would increase to $36 \%$ if all patients got SBI. Similarly, $23 \%$ of risky drinkers in a community visit a pharmacy and reduce their drinking, which would increase to $34 \%$ if they all got SBI. Although our results confirm SBI is costeffective, the impact at the community level is unclear: if

National Drug and Alcohol Research Center, University of New South Wales, Sydney, Australia

C) Biomed Central all GPs and pharmacists delivered SBI to all their risky drinking patients, only $34-36 \%$ would reduce their drinking. A trial that assessed the impact of SBI delivered in multiple settings simultaneously on community level indicators of alcohol harm would move the field toward demonstrating the cost benefit, as well as cost-effectiveness, of SBI.

Published: 9 October 2012

doi:10.1186/1940-0640-7-S1-A13

Cite this article as: Shakeshaft: Screening and brief intervention delivered simultaneously in multiple settings: it is cost-effective, but can it influence community-level outcomes? Addiction Science \& Clinical Practice 2012 7(Suppl 1):A13.

Submit your next manuscript to BioMed Central and take full advantage of:

- Convenient online submission

- Thorough peer review

- No space constraints or color figure charges

- Immediate publication on acceptance

- Inclusion in PubMed, CAS, Scopus and Google Scholar

- Research which is freely available for redistribution 